\title{
Evaluation of sensory properties and their correlation coefficients with physico-chemical indices in Turkish set-type yoghurts
}

\author{
Correlations between sensory and chemical parameters of Turkish yoghurts
}

\author{
Zehra Güler ${ }^{1}$, Young W. Park ${ }^{2^{*}}$ \\ ${ }^{1}$ Department of Food Engineering, Mustafa Kemal University, 31034-Antakya-Hatay, TURKEY \\ ${ }^{2}$ Georgia Small Ruminant Research and Extension Center, Fort Valley State University, Fort Valley, GA 31030,USA; parky@ fvsu.edu
}

Received March 2,2011;revised April 2,2011;accepted April 9,2011

\begin{abstract}
Sensory properties and physico-chemical parameters of 10 most popular brands of commercial set-type Turkish yoghurts were evaluated and correlation coefficients between the two indices were investigated. The results indicated that increases in volatile compounds (acetaldehyde, 2-butanone, 2-nanonane, ethyl acetate), titratable acidity, ash and fat contents inversely correlated with the overall acceptability score of the yoghurt. However, diacetyl, $\mathrm{C}_{4}$ to $\mathrm{C}_{12}$ free fatty acids, $\mathrm{pH}$, whiteness index and texture positively correlated with overall acceptability of the yoghurt products. It was concluded that the acceptability of the Turkish set-type yoghurts is mainly governed by the fifteen volatile compounds as well as the physico-chemical properties determined. Thus, the overall acceptability of the yoghurts was not influenced by a single characteristic, but rather by complex in nature.
\end{abstract}

Keywords: Turkish Set-Type Yoghurt; Sensory Properties; Physico-Chemical Parameters;

Correlation Coefficient

\section{INTRODUCTION}

The sensory quality characteristics of cultured dairy products are not as clearly defined as for other dairy products. Specific geographical differences may exist in consumer preferences for flavor intensity, body and texture characteristics, and /or color and appearance features of many cultured dairy products (Bodyfelt et al. 1988). Consumers are very heterogeneous in their likings and not all consumers prefer sweeter yoghurt. For example, the apparent preference of Turkish consumers is more acid, delicious and fatty flavor of yoghurt. Pohjanheimo and Sandell (2009) have indicated that food choice motives are connected to the liking. Subjects who are considered natural content, ethical concern, and health as important food choice motives perceived sourer, thicker, and more genuine yoghurt flavour as more pleasant, compared to subjects who are considered convenience, price, mood, and familiarity more important, considered sweeter and smoother yoghurt as more pleasant. In addition, brand information is significantly increased the liking for domestic yoghurts but did not alter the main connections between food choice motives and liking.

The sensory properties of Turkish set-type yoghurt as well as gross-chemical composition are stated in Turkish yoghurt standard (TSI 2006). Unfortunately, systematic or routine sensory evaluation of cultured milk products has received less attention than most other traditional dairy products as cheeses. Yoghurt sensory characterristics may be influenced by different factors such as the chemical composition of milk base, type of milk, processing conditions, the ratio, activity and strains of starter culture during the incubation period (Beshkova et al. 1998; Kneifel et al. 1992; Tamime and Robinson 2001; Ulbert and Kneifel 1992).

Since sensory attributes play a key role in determining consumer preference, elucidation of sensory causing components of Turkish yoghurts is of paramount importance to yoghurt producers. In Turkey, yoghurt is one of the greatest volume of dairy products, which is $1,010,000$ tons/per year (FAO 2006). However, no data on the correlations the between sensory and physicochemical properties are available in literature. Thus, the 
aim of this study was to determine the correlations between some physicochemical characteristics and sensory properties of the commercially marketed Turkish set-type yoghurts.

\section{MATERIAL AND METHODS}

\subsection{Preparation of experimental yoghurts}

Ten commercially produced cow milk set-type yoghurts samples from different manufacturers, packaged in PS (Polystrene) plastic cap of about $1 \mathrm{~kg}$, were purchased from local markets in Hatay, Turkey. Taking into consideration packing information, all of the yoghurts were corresponded with regulations stated in Turkish Yoghurt Standart (TSI 2006). Four yoghurt samples were obtained from each brand during two different periods, such as March and December, 2007. All samples were analyzed at the last $14^{\text {th }}$ day before their shelf life expire.

\subsection{Sensory Analysis}

Sensory evaluation was performed by 14 experienced panelists (ten males and four female) who have been trained with yoghurt sensory scores characteristics. The panel consisted of academic staff and students from Food Engineering Department of Mustafa Kemal University, Hatay, Turkey. Yoghurts were removed from refrigerator $\left(4^{\circ} \mathrm{C}\right) 1 \mathrm{~h}$ prior to sensory evaluation, kept at room temperature $\left(22 \pm 2^{\circ} \mathrm{C}\right)$. Appearance (unnatural color to natural color), acid taste and atypical yoghurt flavor scores by hedonic scales (none to extremely strong) rated immediately after opening yoghurt caps. Whey drainage was examined by visually observing the gel surface of the products and after inserting a spoon into gel. The evaluation of the texture (weak to very firm) was also based on visual observation after stirring the product with spoon. Each sensory attribute was clearly defined to the panelists as described by Bodyfelt et al. (1988). The intensity of sensory attributes was measured on a 4-point hedonic scale where 3 corresponded to 'much too strong' and 0 corresponded to 'none'. By using a 9 -point hedonic sale $(1=$ dislike extremely, $5=$ neither like nor dislike, $9=$ like extremely), consumers rated overall acceptability. Yoghurt was evaluated in duplicate by the panel members.

\subsection{Chemical Analyses}

\subsubsection{Analyses of basic nutrients and physicochemical indices}

Total solids, fat, protein, ash contents and titratable acidity value of yoghurts were determined according to the Association of Official Analytical Chemist (AOAC, 2003) methods. $\mathrm{pH}$ was measured using a $\mathrm{pH}$ meter (Orion, Thermo, USA). Lactose content was estimated as the difference between total solids and the sum of fat, protein and ash contents.

Color characterisitcs were measured by using a Minolta Chromameter (model CR-400 Tokyo, Japan) calibrated with a manufacturer-supplied white calibration plate. The $L($ dark $=0$ and light $=100), a($ red $=$ $+a$ and green $=-a)$ and $b($ yellow $=+b$ and blue $=-b)$ values were measured. The $L^{*}, a^{*}$ and $b^{*}$ reading was carried out in triplicate for each sample. Results were expressed as Chroma $\left(C^{*}=\left[\left(a^{*}\right)^{2}+\left(b^{*}\right)^{2}\right]^{0.5}\right)$, hue angle $\left(h_{\mathrm{ab}}=\tan ^{-1}\left[\left(a^{*}\right)\left(b^{*}\right)^{-1}\right]\right)$, and whiteness index $(W I=100$ $\left.-\left[(100-L)^{2}+a^{2}+b^{2}\right]^{0.5}\right)$. Analyses were carried out in duplicate obtaining Two yoghurt samples from each the brand were collected at two experimental period (March and December, 2007), and each sample was analyzed in duplicates.

\subsubsection{Analyses of free fatty acids (FFA) and benzoic acid}

Extraction and quantification of FFA and benzoic acid were carried out according to the method of Deeth et al. (1983) with slight modifications as reported by Güler (2008). Heptanoic acid was added to all experimental yoghurt samples at the time of extraction. FFAs were analyzed by a GC-MS (Agilent 6890 gas chromatograph and 5973 N mass selective detector; Agilent, Palo Alto, CA, USA). Column used for FFA and benzoic acid separation was a DB-FFAP-column $(30 \mathrm{~m} \times 0.25 \mathrm{~mm}$ id $\times 0.25 \mu \mathrm{m}$ film thickness). Analyses were carried out in triplicate.

For GC operating conditions of FFA and benzoic acid analysis, helium was used as a carrier gas with a constant flow rate of $1 \mathrm{~mL} \mathrm{~min}^{-1}$. The GC oven temperature was set to $50^{\circ} \mathrm{C}$ for $5 \mathrm{~min}$ then raised to $230^{\circ} \mathrm{C}$ at a rate of $5^{\circ} \mathrm{C} \mathrm{min} \mathrm{min}^{-1}$ and held at $230^{\circ} \mathrm{C}$ for $20 \mathrm{~min}$. The injector temperature was $250^{\circ} \mathrm{C}$, and the run time was 58 min. The GC column was connected without splitting to the ion source of the Agilent 5973N model quadrupole mass selective detector which was operating in the scan mode within a mass range 33 to $330 \mathrm{~m} \mathrm{z}^{-1}$ at 1 scan s$^{-1}$. The interface line to MS was set at $280^{\circ} \mathrm{C}$. The MS was operated in an electron impact mode at electron energy of $70 \mathrm{eV}$ and was calibrated by auto-tuning. Identification of the compounds was performed by a computermatching of their mass spectral data with those of known compounds from the Mass Spectral Database (Wiley7n.1 /Nist02.L.). To compensate the amount of loss during the extraction and clean-up, heptanoic acid $\left(\mathrm{C}_{7}\right)$ was used as internal standard. Pre-analyses of the milk and yoghurt had ensured that heptanoic acid was absent. 


\subsubsection{Analysis of volatile compounds (VC)}

VCs were determined by static head space technique according to Güler (2007). VCs were analyzed using a Agilent model 6890 gas chromatography (GC) and 5973 $\mathrm{N}$ mass selective detector (MS) (Agilent, Palo Alto, CA, USA). Columns used for FFA separation HP-INNOWAX capillary column $(30 \mathrm{~m} \times 0.32 \mathrm{~mm}$ id $\times 0.25 \mu \mathrm{m}$ film thickness). The volatile compounds were separated under the following conditions: injector temperature $200^{\circ} \mathrm{C}$; carrier gas helium at a flow rate of $1.4 \mathrm{~mL} \cdot \mathrm{min}^{-1}$; oven temperature program initially held at $50^{\circ} \mathrm{C}$ for 6 min and then programmed from $50^{\circ} \mathrm{C}$ to $180^{\circ} \mathrm{C}$ at $8{ }^{\circ} \mathrm{C} \cdot \mathrm{min}^{-1}$ held at $180^{\circ} \mathrm{C}$ for $5 \mathrm{~min}$. The interface line to $\mathrm{MS}$ was set at $250^{\circ} \mathrm{C}$. Identification of the compounds was also conducted by a computer-matching of their mass spectral data with those of known compounds from the Nist 02.L. Mass Spectral Database. Based on the peak resolution, their areas were estimated from the integrations performed on selected ions. The resulting peak areas were expressed in the arbitrary area units. Quantification of constituents was calculated by external standard technique.

\subsection{Statistical Analysis}

Statistical analysis was performed using the SPSS version 9.05 for Macintosh (SPSS Inc./Chicago, III., U.S.A.). Data were expressed as means \pm standard deviation. The coefficient of variation $(\mathrm{CV})$ between the samples was expressed as relative standard deviation (\%). Sensory properties were submitted to one-way analysis of variance (ANOVA). Duncan multiple mean comparison test $(\mathrm{P}<0.05)$ was used to state the differences among the yoghurts. Pearson's correlation coefficient (r) was also performed measure of the strength of the association between the variables. Linear Discriminat Analysis was applied to detect the presence of classes within the yoghurt samples. The variables were selected by forward stepwise analysis, and Wilk's lambda and F-value were used to determine the significance of the changes in lambda when a new variable is tested. Validation of these results was performed by leave-one-out cross validation.

\section{RESULT AND DISCUSION}

Results of sensory evaluation on the yoghurt samples are presented in Figure 1. None of the yoghurts received the maximum overall acceptability score of 9 (excellent) described by the sensory evaluation form. Linear Discriminant Analysis (LDA) was applied to distinguish among yoghurt samples. Using the yoghurt samples as a classification variable, the selected variables were the scores of sensory properties. LDA achieved a high recognition percentage for the classification of yoghurt samples according to the sensory properties, reaching a percentage of $91.2 \%$ for yoghurt samples (Figure 2). According to the sensory scores, yoghurt samples fell

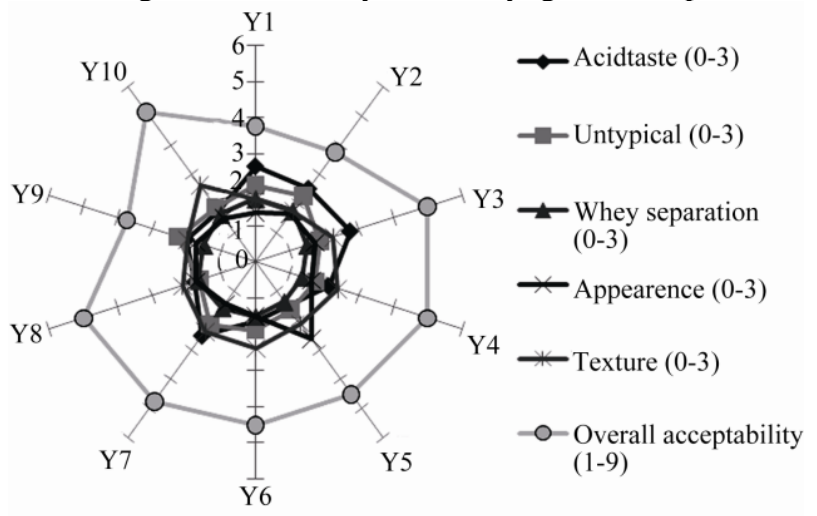

Figure 1. The sensory evaluation of yoghurt samples obtained from 10 brands.

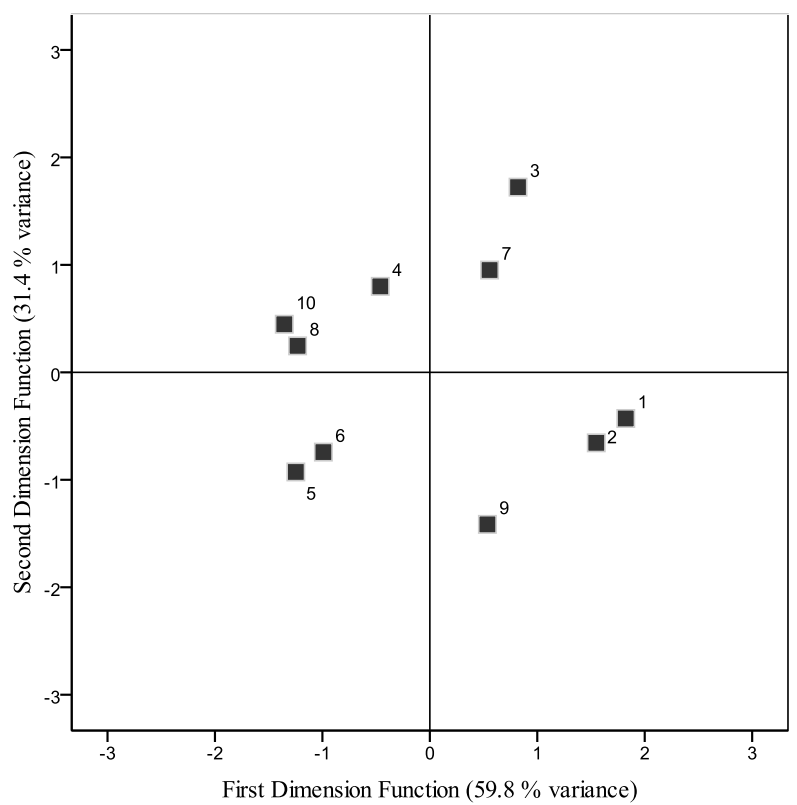

Figure2. Scattered plot of the samples projected in the plane defined by the discriminant functions according to sensory properties.

into four distinct groupings, where each group consisted of yoghurts samples with similar characteristics. As shown in Table 1, yoghurts are predominantly grouped according to the magnitude of overall acceptability and texture scores. This indicates that panelists were able to distinguish differences among samples, as well as to make similar assessments for duplicates within a sample.

There were significant differences in acid $(\mathrm{P}<0.001)$ and atypical $(\mathrm{P}<0.05)$ taste scores in yoghurt samples (Table 1). Pearsons correlation coefficeints of acid taste 
scores were significant with titratable acidity $(0.61, \mathrm{P}<$ $0.001)$, appearence $(-0.59, \mathrm{P}<0.001)$ and overall acceptability $(-0.57, \mathrm{P}<0.001)$. Similar results were Table 1. Sensory properties of yoghurts grouped according to Linear Discriminant Analysis (LDA).

\begin{tabular}{|c|c|c|c|c|c|c|c|}
\hline \multirow[b]{2}{*}{${ }^{1}$ Properties } & \multicolumn{4}{|c|}{ Yoghurt samples } & \multirow[b]{2}{*}{ Mean $^{\mathrm{a}}$} & \multirow[b]{2}{*}{$\mathrm{P}$} & \multirow[b]{2}{*}{$\mathrm{CV}$} \\
\hline & Y1-Y2-Y9 & Y5-Y6 & Y3-Y7 & Y4-Y8-Y10 & & & \\
\hline Acid taste $(0-3)$ & $2.38 \pm 0.34$ & $1.57 \pm 0.09$ & $2.63 \pm 0.18$ & $1.88 \pm 0.22$ & $2.12 \pm 0.46$ & $* * *$ & 21.54 \\
\hline Atypical(0-3) & $2.21 \pm 0.07$ & $1.76 \pm 0.18$ & $2.01 \pm 0.18$ & $1.75 \pm 0.13$ & $1.94 \pm 0.24$ & * & 12.19 \\
\hline Appearence (0-3) & $1.59 \pm 0.19$ & $2.07 \pm 0.81$ & $1.59 \pm 0.23$ & $1.63 \pm 0.13$ & $1.70 \pm 0.36$ & $* * *$ & 21.09 \\
\hline Texture $(0-3)$ & $1.83 \pm 0.14$ & $2.25 \pm 0.19$ & $2.32 \pm 0.09$ & $2.38 \pm 0.25$ & $2.18 \pm 0.29$ & $*$ & 13.15 \\
\hline${ }^{2}$ Overall acceptability (1-9) & $3.75 \pm 0.01$ & $4.50 \pm 0.00$ & $4.88 \pm 0.18$ & $5.04 \pm 0.08$ & $4.51 \pm 0.57$ & $* * *$ & 12.57 \\
\hline
\end{tabular}

${ }^{\mathrm{a}}$ Means \pm standard deviations of 40 yoghurt samples; P: significant level; NS: non significant; $* \mathrm{P}<0.05 ; * * * \mathrm{P}<0.001$; ${ }^{1}$ Zero-3 points intensity scale; ${ }^{2}$ One- 9 points scale. $(1=$ dislike extremely, $5=$ neither like nor dislike, $9=$ like extremely); CV; Coefficients of variation (standard deviation/mean $\times 100)$.

(1991). No significant differences in whey separation scores of yoghurt samples were observed (Table 1). Whey separation in the yoghurts was correlated with $\mathrm{pH}$ (0.380, $\mathrm{P}<0.01)$. Appearence (color) score of yoghurts was significantly different from each other $(\mathrm{P}<0.05)$. Appearance was also significantly correlated with whiteness index $(0.278, \mathrm{P}<0.05), \mathrm{h}_{\mathrm{ab}}(-0.291, \mathrm{P}<0.05)$, titratable acidity $(-0.309, \mathrm{P}<0.05)$ values and overall acceptability $(0.56, \mathrm{P}<0.01)$. One of the most important sensory attributes for yogurt is texture (Sodini et al. 2004). There were significant differences in texture scores between yoghurt samples $(\mathrm{P}<0.05)$ (Table 1 ). Texture scores has significant correlation coefficients with protein $(0.293, \mathrm{P}<0.05)$, ash $(-0,308, \mathrm{P}<0.05)$, whiteness index $(0.444, \mathrm{P}<0.01)$ and $\mathrm{pH}(-0.280, \mathrm{P}<$ $0.05)$. The more acidic yoghurt samples revealed the more firm texture, which is in agreement with the report by Chammes et al. (2006). According to Modler et al. (1983), increasing amounts of proteins in milk formulation increased gel firmness of yogurt. Moreover, yogurt viscosity was improved as a result of the increasing of dry matter (Skriver et al. 1999). Texture of the Turkish yoghurts in this study was positively correlated with overall acceptability $(0.479, \mathrm{P}<0.01)$, which was similar to the data reported by Harper et al. (1991).

Significant correlation coefficients were found between scores of the sensory attributes and physiccochemical properties of the commercial Turkish yoghurts as shown in Table 2. The correlation coefficient of acetaldehyde (sharp, green and white glue) (Lindisay et al. 1965; Harper et al. 1991) was positive with atypical taste $(0.40, \mathrm{P}<0.01)$, and negative with overall acceptability $(-0.39, \mathrm{P}<0.05)$. These observations are coincided with the report by Barnes et al. (1991). Even though acetone did not have a significant correlation with overall acceptability, it was significantly and negatively correlated with acid taste. Warsy (1983) indicated that acetone may have limited importance for yoghurt flavor. The mean value $\left(6.9 \mu \mathrm{g} \cdot \mathrm{g}^{-1}\right)$ of aceton (data shown in the previous paper) is markedly low in yoghurts when compared to the threshold in water $\left(40.9 \mu \mathrm{g} \cdot \mathrm{g}^{-1}\right)$ (Molimard and Spinnler 1996). On the other hand, correlation coefficient of diacetyl, which is responsible for buttery flavor (Macciola et al. 2008), was positive and significant with both acid taste $(0.37, \mathrm{P}<0.05)$ and overall acceptability $(0.53, \mathrm{P}<0.01)$. This could be attributable to the high mean content $\left(5.1 \mu \mathrm{g} \cdot \mathrm{g}^{-1}\right)$ of diacetyl (data shown in the previous paper) when compared with threshold in water $\left(0.2 \mu \mathrm{g} \cdot \mathrm{g}^{-1}\right)$ (Molimard and Spinnler 1996). This finding is in agreement with the report by Rysstad and Abrahamsen (1987). The presence of diacetyl is thought to contribute to the delicate, full flavor and aroma of yoghurt, and their presence are important if acetaldehyde content is low (Beshkova et al. 1998).

Regarding to the other aromatic volatiles, 2-butanone (acetone), 2-nonanone (fruity, musty) and ethyl acetate (fruity) were believed to be responsible for various taste and odor (Molimard and Spinnler 1996), but had negative correlations with overall acceptability in our study (Table 2). 2-Nanonane and 2-tridecanone (fruity, green) showed positive correlation coefficients with atypical flavor, since ketones with a higher carbon number are responsible for heated milk flavor as described by Badings et al. (1981).

As far as free fatty acids are concerned, butanoic (rancid, cheesy), hexanoic (pungent, sour), octanoic (waxy, goaty), decanoic (rancid, fatty) and dodecanoic (fatty) acids (Sable and Cottenceau 1999) were positively and significantly correlated with overall acceptability of the yoghurts (Table 2). This suggests that these free fatty acids may contribute to the formation of the specific flavor-aromatic properties of set-type Turkish yoghurts as reported earlier by other researchers (Warsy 1983; Beshkova et al. 1998; Stelios et al. 2007). The mean values of $\mathrm{C}_{4}\left(6.2 \mu \mathrm{g} \cdot \mathrm{g}^{-1}\right), \mathrm{C}_{6}\left(7.8 \mu \mathrm{g} \cdot \mathrm{g}^{-1}\right)$ and $\mathrm{C}_{8}(2.5$ $\left.\mu \mathrm{g} \cdot \mathrm{g}^{-1}\right)$ free fatty acids in the yoghurt samples 
(Y1,Y2,Y9) had low overall acceptability scores (Table 1), which were lower than odour threshold reported by Rychlik et al. (2006). On the other hand, the mean concentrations of free fatty acids $C_{4}\left(10.5 \mu \mathrm{g} \cdot \mathrm{g}^{-1}\right)$ and $\mathrm{C}_{6}$ $\left(14.5 \mu \mathrm{g} \cdot \mathrm{g}^{-1}\right)$ in yoghurts (Y4, Y8 and $\left.\mathrm{Y} 10\right)$ having high overall acceptability were higher than odour thresholds Table 2. The significant pearson's correlation coefficients between physicochemical and sensory propertie.

\begin{tabular}{lccc}
\hline Component & Acid taste & Untypical & $\begin{array}{c}\text { Overall } \\
\text { acceptability }\end{array}$ \\
\hline Acetaldehyde & $0.46^{* *}$ & $0.40^{* *}$ & $-0.390^{*}$ \\
Acetone & $-0.47^{* *}$ & -0.22 & 0.19 \\
Diacetyl & 0.37 & -0.18 & $0.53^{* *}$ \\
2-Butanone & -0.03 & $0.28^{*}$ & $-0.34^{*}$ \\
2-Nanonane & 0.20 & $0.29^{*}$ & $-0.36^{*}$ \\
2-Tridecanone & 0.16 & $0.30^{*}$ & 0.00 \\
Ethylacetate & 0.202 & $0.458^{* *}$ & $-0.340^{*}$ \\
Butanoic acid (C4) & -0.13 & -0.22 & $0.35^{*}$ \\
Hexanoic acid (C6) & -0.15 & -0.24 & $0.34^{*}$ \\
Octanoic acid (C8) & -0.17 & $-0.34^{*}$ & $0.58^{* *}$ \\
Decanoic acid (C10) & -0.11 & $-0.34^{*}$ & $0.59^{* *}$ \\
Dodecanoic acid & & & \\
(C12) & -0.02 & -0.21 & $0.32^{*}$ \\
Fat & 0.18 & 0.37 & $-0.41^{* *}$ \\
Titratable acidity & $0.40^{* *}$ & 0.07 & $-0.32^{*}$ \\
PH & 0.00 & $-0.31^{*}$ & $0.48^{* *}$ \\
Ash & -0.08 & 0.272 & $-0.55^{* *}$ \\
Whitenes index & -0.20 & 0.18 & $0.44^{* *}$ \\
Texture & -0.118 & -0.23 & $0.48^{* *}$ \\
\hline
\end{tabular}

$* \mathrm{P}<0.05$ and $* * \mathrm{P}<0.01$

of $\mathrm{C}_{4}\left(6.58 \mu \mathrm{g} \cdot \mathrm{g}^{-1}\right)$ and $\mathrm{C}_{6}\left(13.63 \mu \mathrm{g} \cdot \mathrm{g}^{-1}\right)$, whereas the amount of $\mathrm{C}_{8}\left(6.7 \mu \mathrm{g} \cdot \mathrm{g}^{-1}\right)$ was lower than threshold $\left(13.23 \mu \mathrm{g} \cdot \mathrm{g}^{-1}\right)$ in yoghurt. This result may confirm that if the level of octanoic acid, which is responsible for goaty and waxy flavor, is high in yoghurts, it can negatively affect overall acceptability. The concentration $\left(5.3 \mu \mathrm{g} \cdot \mathrm{g}^{-1}\right)$ of decanoic acid is responsible for rancid and fatty flavor in yoghurts with low overall acceptability score, which is almost close to thresholds in oil or butter $\left(5 \mu \mathrm{g} \cdot \mathrm{g}^{-1}\right)$, while it is higher than that in water (3.5 $\left.\mu \mathrm{g} \cdot \mathrm{g}^{-1}\right)$. In yoghurts with high overall score, concentration $\left(9.7 \mu \mathrm{g} \cdot \mathrm{g}^{-1}\right)$ of decanoic was higher than threshold in oil.

Concerning dodecanoic acid responsible for fatty flavor, its mean concentration $\left(11.4 \mu \mathrm{g} \cdot \mathrm{g}^{-1}\right)$ in yoghurts with low and high overall acceptability score was higher and lower than threshold in water $\left(2.2 \mu \mathrm{g} \cdot \mathrm{g}^{-1}\right)$ and oil $\left(50 \mu \mathrm{g} \cdot \mathrm{g}^{-1}\right)$, respectively (Molimard and Spinnler 1995; Sable and Cottenceau 1999). This result confirmed that if dodecanoic acid was much higher in yoghurts than threshold in oil, it might be negatively correlated to overall acceptability since the correlation coefficient between fat content and overall acceptability score was negative. This indicates that the correlation between volatile free fatty acids and overall acceptability is probably due to odour threshold of each free fatty and characteristic flavor.

On the other hand, a synergistic action of the shortchain acids may be suggested. For example, compounds with similar odour attributes occurring in sub-threshold concentration may enhance each other and thus are detected. Ethanoic (acetic) acid responsible for harshness flavour described as "vinegary" (Molimard and Spinnler 1996; Sable and Cottenceau 1999) did not have a significant correlation with overall acceptability, since the mean value $\left(15.3 \mu \mathrm{g} \cdot \mathrm{g}^{-1}\right)$ of ethanoic acid in yoghurts was lower than minimum threshold $\left(22 \mu \mathrm{g} \cdot \mathrm{g}^{-1}\right)$ in water. In addition, the perception of acetic acid by panelists might be masked by the other free fatty acids.

There were significant correlations between titratable acidity $(-0.39, \mathrm{P}<0.05), \mathrm{pH}(0.31, \mathrm{P}<0.05)$ and overall acceptability (Table 2). High acidity negatively influenced the overall acceptability, as similar results were observed by various researchers (Harper et al. 1991; Kneifel et al. 1992; Ott et al. 2000), where they emphasized the importance of acidity in yogurt flavor. In contrast, Barnes et al. (1991) suggested that there were no relationships betweem any sensory and analytical measurement for predicting the overall liking of plain yogurt. However, for US consumers, the relatively high extent of sourness along with the intensity of acetaldehyde (the key volatile compound of yogurt) have resulted in low consumer acceptance (Barnes et al. 1991).

Concerning other parameters, ash $(\mathrm{P}<0.01,-0.55)$ and fat $(\mathrm{P}<0.01,-0.41)$ had a negative correlations with overall acceptability, while whitenes index $(\mathrm{P}<0.05$, $0.44)$ and texture $(\mathrm{P}<0.01,0.48)$ had a possitive correlation coefficient (Table 2). In fact, texture of yoghurt could affect the perception of volatile compounds during consumption and also the final quality of product, as suggested by other investigators (Kneifel et al. 1992; Serra et al. 2009).

\section{CONCLUSION}

There were positive and significant correlations between free fatty acids $\left(\mathrm{C}_{4}-\mathrm{C}_{12}\right), \mathrm{pH}$, whiteness index and texture and overall acceptability score of Turkish set-type yoghurts. However, increases in the amounts of some volatile compounds (acetaldehyde, acetone, 2-butanone, 2-nonanone, etyl acetate,) and titratable acidity value caused a decrease in overall acceptability of yoghurt. Thus, understanding and controlling the overall acceptability of a yoghurt would be still difficult due to the differences in relative distribution of sensorially active compounds exerting a main effect. In addition, overall acceptability scores of yoghurts may be influ- 
enced by consumers' ethical concern, health, sex and age, etc.

\section{ACKNOWLEDGEMENTS}

The authors gratefully acknowledge the members of the sensory panel conducted this study. We also thank Gökhan DILLER and Ersin GÖK for assisting in labratory analyses.

\section{REFERENCES}

[1] Badings H T, Van der Pol JG and Neeter R (1981) Aroma compounds which contribute to the difference in flavor between pasteurized milk and UHT milk. In Flavor '81', pp 685-692, Schreier P, ed. Berlin: Walter de Gruyter.

[2] Barnes DL, Harper SJ, Bodyfelt FW and McDaniel MR (1991) Prediction of consumer acceptability of yogurt by sensory and analytical measures of sweetness and sourness. Journal Dairy Science 74 3746-54.

[3] Beshkova D, Simova E, Frengova G and Simov Z (1998). Production of flavour compounds by yogurt starter cultures. J. Industrial Microbiology \& Biotechnology, 20, 180-186

[4] Bodyfelt FW, Tobias J, Trout GM (1988) The sensory evaluation of dairy products. Pp.598. New York, USA: Van Nostrand Reinhold.

[5] Chammas G, Saliba R and Beal C (2006) Characterization of the Fermented Milk "Laban" with Sensory Analysis and Instrumental Measurements Journal of Food Science 71 156-162.

[6] FAO (2006) Food Agricultural Organization. www.faostat.fao.org

[7] Harper SJ, Barnes DL, Bodyfelt FW and McDaniel MR (1991) Sensory ratings of commercial plain yogurts by consumer and descriptive panels. Journal Dairy Science 74 2927-35.

[8] Kneifel W, Ulbert F, Erhard F and Jaros D (1992) Aroma profiles and sensory properties of yoghurt and yoghurt related products. I. Screening of commercially available starter cultures. Milchwissenchaft 47 362-365.

[9] Lindsay R C, Day E A and Sandine W E (1965) Green flavor defect in lactic starter cultures. Journal Dairy Science 48863.

[10] Macciola V, Candela G and De Leonardis A (2008) Rapid gas-chromatographic method for the determination of diacetyl in milk, fermented milk and butter. Food Control 19 873-878.

[11] Modler HW, Larmond ME, Lin CS, Froehlich D, and Emmons DB (1983) Physical and

[12] sensory properties of yogurt stabilized with milk proteins. Journal Dairy Science 66 422-9.
[13] Molimard P and Spinnler HE (1996) Compound Involved in the Flavor of Surface Mold-Ripened Cheeses: Origins and Properties. Journal of Dairy Science 79 169-184.

[14] Ott A, Germond JE and Chaintreau A (2000) Vicinal diketone dormation in yoghurt: $13 \mathrm{C}$ precursors and effect of branched-chain amino acids. Journal of Agricultural and Food Chemistry 48 724-731.

[15] Pohjanheimo T and Sandell M (2009) Explaining the liking for drinking yoghurt: The role of sensory quality, food choice motives, health concern and product information. International Dairy Journal 19 459-466.

[16] Rychlik M, Sax M and Schieberle P (2006) On the role of short-chain free fatty acids for the development of a cheese-like off-note in pasteurized yoghurt. LWT 39 521-527.

[17] Rysstad G and Abrahamsen RK (1987) Formation of volatile aroma compounds and carbon dioxide in yogurt starter grown in cows' and goats' milk Journal of Dairy Research 54 257-266.

[18] Sable S and Cottenceau G (1999) Current Knowladge of Soft Cheeses Flavor and Related Compounds. Journal Agricural Food Chemistry 47 4825-4836.

[19] Serra M, Trujillo AJ, Guamis B and Ferragut V (2009) Flavour profiles and survival of starter cultures of yoghurt produced from high-pressure homogenized milk. International Dairy Journal 19 100-106.

[20] Skriver A, Holstborg J and Qvist KB (1999) Relation between sensory texture analysis

[21] and rheological properties of stirred yogurt. Journal Dairy Research 66 609-18.

[22] Sodini I, Remeuf F, Haddad S and Corrieu H (2004) The Relative Effect of Milk Base,

[23] Starter, and Process on Yogurt Texture: A Review Critical Reviews in Food Science and Nutrition $\mathbf{4 4}$ 113-137.

[24] Stelios K, Stamou P and Massouras T (2007) Comparision of The Characterstics of Set Type Yohurt Made From Ovine Milk of Different Fat Content. International Journal Food Science and Technology 42 1019-1028.

[25] Tamime A Y and Robinson RK (2001) Yoghurt Science and Technology. pp 619, New York US: CRC Pres.

[26] TSI (2006) Yogurt. TS 1330. Ankara: Turkish Standar Institution.

[27] Ulbert F and Kneifel W (1992) Aroma profiles and sensory properties of yoghurt and yoghurt-related products. II. Classification of starter cultures by means of cluster analysis. Milchwissenchaft 47 432-434.

[28] Warsy J D (1983) production of volatile aroma compounds in Dahi. Journal Agricultural Research 21 (1) 31-36. 